\title{
Temperature Calibration Measurements based on Laser-Induced Phosphorescence Technique for Combustion Applications
}

\author{
A Jaber ${ }^{a, b, c^{*}}$ \\ ${ }^{a}$ Department of Mechanical and Industrial Engineering, Faculty of Engineering, The Applied Science \\ University (ASU), Amman Jordan, 11931. \\ ${ }^{b}$ Erlangen Graduate School in Advanced Optical Technologies (SAOT), Friedrich-Alexander-Universitaet \\ Erlangen-Nuernberg, Erlangen, Germany, D-91052. \\ ${ }^{c}$ Lehrstuhl fuer Technische Thermodynamik (LTT), Friedrich-Alexander-Universitaet Erlangen-Nuernberg, \\ Erlangen, Germany, D-91058.
}

\begin{abstract}
Phosphor powder and phosphor-binder mixtures are successfully employed for temperature calibration measurements by using laser-induced phosphorescence (LIP) technique with an emphasis on higher precisions and accuracies than other non-intrusive methods. The phosphorescence intensities are used to perform these calibrations in three different strategies. The influence of laser power regular changes on particles heating and the calibration analyses is also carried out. A pulsed laser at $355 \mathrm{~nm}$ was used for exciting specimens of the phosphor powder as well as the phosphor-binder mixtures. The laser beam was directed onto the specimens and varied in three laser power levels (LPLs). The samples were kept in an oven with temperatures ranging from room temperature up to $1800{ }^{\circ} \mathrm{C}$. The three strategies which are expressed in terms of non-dimensional intensity versus wavelength (NDI-W), normalised intensity (NI) and intensity ratio (IR) were used for the calibration assessments. A modified IR was compared with two different IRs. A precision of around $\pm(0.50-1.41) \%$ was attained for different calibration methods.

This research confirmed that these calibrations are possible using three different strategies, given high precisions and accuracies. The laser power alternations influenced the NI and do affect neither the NDI-W nor the IR curves. The laser radiation does not play any role for heating the particles of the studied powder.
\end{abstract}

Keywords: phosphorescence behaviour, calibration curves, particles heating, intensity ratio.

\section{Introduction}

Temperature determinations play a vital role in fields of engineering, natural science, atmospheric sciences, physics, chemistry, geology and biology.

Optical measurement techniques are characterised by a free access to targets, low interferences with the target and its ambient, high survivability in harsh environmental conditions, large accuracies and precisions. In contrast, although conventional techniques, such as Langmuir probes, resistance temperature, thermocouples, thermistors and detectors are

${ }^{*}$ Corresponding author. Tel.: +96265609999 ext.: 1290

Fax: +96265232899; E-mail: a_jaber@asu.edu.jo

(C) 2015 International Association for Sharing Knowledge and Sustainability

DOI: $10.5383 /$ ijtee.10.01.006 widely used, but they experience from access limitations, high interferences, low endurance, small accuracies and precisions. Also, some of non-intrusive systems for thermometry, such as thin filament pyrometries and pyrometers undergo either from low endurance and/or high inaccuracies and imprecisions.

Therefore, a robust less or non-intrusive temperature calibration measurements technique giving high accuracies and precisions is required. A technique for such measurements can be made using thermographic phosphor also called phosphor thermometry, through its illuminations or phosphorescence after laser excitation.

The phosphor used in the thermometry is usually inorganic, undergoes extremely high temperatures, comes in a diameter of 
0.1-10 $\mathrm{m}$ [1-19] or larger [17-19] and has the form of white, red, ruby, green and blue [6, 8-15, 20-25]. It consists of a host material and one doping agent $[1-11,14-45]$ or more [11-13, 26] from which the light is emitted. The chosen phosphor thermography in this study consists of dysprosium-doped yttrium aluminium garnet (Dy:YAG) and a supplementary activator erbium (Er). The dopants or the activators are excited by energy absorption to a higher electronic energy level from non-radiating transitions, to stable levels ending with emissions appearance in spiky spectral lines. These lines are temperature dependent and used for phosphor thermometry after appropriate calibrations. These calibrations can be performed in terms of spectral distribution, lifetime decay and intensity ratios to remotely measure the temperatures. The unknown temperatures in applied experiments can be later identified by using these calibrations under well controlled conditions.

Laser-induced phosphorescence (LIP) has been developed and used in proof-of-principle studies for temperature calibrations and measurements in the early 1980's until the present, showing that both are possible in adverse environments [1-45]. It was widely used for surface temperature measurements of coated components, e.g., in high corrosive high temperature conditions [5-18, 20-37, 41-44]. These environments occur in internal combustion engines, furnaces, pressure chambers, gas turbines, flames, heaters, porous media burners (PMBs), fire spraying systems, combustion chambers, gaseous free-flow applications, conventional burners, gas centrifuges, extremely fast moving objects, safety applications, electrical machinery, wind tunnels, aeropropulsion applications, reacting and nonreacting materials, rotors in permanent-magnet motors, single particle pyrolysis reactors, air jets and gaseous temperature measurements in combustion [1-37, 44].

Temperature measurements are made through seeding or atomising a flow stream with phosphor particles [1-6, 11, 19, $44,45]$, coating surfaces either by pure phosphor $[6,11,13-18$, $20-23,29-32,37]$ or with a mixture of phosphor and an adhesive agent [5-12, 24-28, 36, 40, 44]. The phosphorescence from the seeded particles, the atomised ones and the phosphorcoated components will determine the temperature, assuming that thermal equilibrium is reached.

The spectral distribution of phosphorescence also called photoluminescence temperature-dependent is used for temperature measurements [1-3, 6-8, 11-14, 18, 27, 35-39] and other applications. For instance, the phosphorescence spectra of phosphor deposited films and powders were used in the range of $300-1000 \mathrm{~K}$ to identify the properties of temperature luminescent [14]. The distribution provided with various phosphor mixtures was used to develop the modules of mediumbrightness light emitting diodes in a temperature range of 2703-4000 K [37]. It was also used in a temperature range of 298-523 K to study the thermal quenching behaviour through a warm white light-emitting diode using a yellow-emitting carbonitride phosphor [38]. The recorded photoluminescence spectra at $1473 \mathrm{~K}$ of a sintered Eu:YAG was used to improve the luminescence efficiency of phosphors used for cathode ray tube screens and high-definition projection TVs [39].

Temperature measurements are also performed using a well known way, called phosphorescence decay time [4-6, 8-11, 15$17,21-35,42]$.The emitted signals after laser excitation is detected point wise by photomultipliers to determine the lifetime decay. Another way for temperature assessments is made through intensity ratios. The intensity ratio is determined by detecting two different wavelengths using, for instance, two cameras, photomultipliers, spectrometers, spectroscopes and imaging the same object through two different pathways onto one camera chip $[1-3,5-8,11-14,18-21,24,31,40-43]$.
Surface temperature measurements of combusting rocket propellant were feasible using the intensity ratio of 'laserinduced fluorescence (LIF) phosphor thermometry' [18]. Moreover, a ratio method uses two different wavelengths showed analytically the ability to remove the spatially distributed effects of both illumination and emission intensities [25]. A 'LIF thermal imaging system' was developed as well, capable of accurate $\left( \pm 0.5^{\circ} \mathrm{C}\right) 2 \mathrm{D}$ temperature measurements on a relatively small flat surface using two different emission lines of europium-doped lanthanum oxysulfide phosphor thermometry $[41,42]$. It is essential to note that phosphor thermometry allows for temperature detection up to $1673 \mathrm{~K}$ for phosphor types, such as Dy:YAG with uncertainties better than for other remote standard techniques, such as pyrometry $[10$, 29]. In contrast, these inaccuracies in other investigations are very high, e.g., $\pm 10.7 \%$ for a combined standard uncertainty [20] and up to $20 \%$ at $673 \mathrm{~K}$ [22]. Thus, advanced studies are required.

In a previous research, the authors adapted a LIP technique for temperature calibrations using normalised intensity (NI) and intensity ratio (IR) charts in a range of $293-2073 \mathrm{~K}$ and proved that these calibrations are attainable [13]. An ultraviolet (UV) pulsed neodymium-doped yttrium aluminium garnet (Nd:YAG) laser at a wavelength of $355 \mathrm{~nm}$ was used for phosphor Dy:Er:YAG excitations. The phosphorescence behaviour was described in six strategies and the intensity ratios were calculated in three ways; a laser power level of 5.4$54 \mathrm{~mJ} /$ pulse called LPL 1 was used [13].

The objective of this study is to use the charts of nondimensional intensity wavelength (NDI-W), NI and IR for temperature calibrations in the range of $293-2073 \mathrm{~K}$ and to study the effect of laser power changes on these calibrations due to particles heating which is new in many aspects.

Moreover, the precision in terms of the standard deviation based on the entire population $\left(\mathrm{SD}_{\mathrm{p}}\right)$ for the three aforesaid calibrations is investigated.

\section{Experimental setup and procedure}

The experimental setup presented in Fig. 1 can be described as follows: a sample of phosphor powder (1) is heated in an oven (2) under varying temperatures from 293-2073 K with a reproducible regulating accuracy of $\pm 2 \mathrm{~K}$ [46]. An UV pulsed Nd:YAG laser (3) is used for the phosphor excitations. The laser operating conditions were: a frequency of $10 \mathrm{~Hz}$, an exposed area of $0.75 \mathrm{~mm}^{2}$ and a wavelength of $355 \mathrm{~nm}$. The LPL 2 and LPL 3 were: $5.58-55.8 \mathrm{~mJ} / \mathrm{pulse}$ and $9.0-90 \mathrm{~mJ} / \mathrm{pulse}$, respectively. Also, 90-120 mJ/pulse is infrequently used for extremely weak signals. The LPL 1 and LPL 2 were defined to be $60 \%$ and $62 \%$ of LPL 3, respectively. The lower and the upper limits of the LPLs were chosen to provide sufficient excitations, to avoid phosphorescence saturation effects and to check the influence of laser radiation on particles heating. Due to these issues, the laser power was not kept to be fixed for the entire temperature range. The laser beam is applied to the sample in the oven resulting in sufficient excitations. The excited phosphor emits phosphorescence. The spectrum of phosphorescence is measured using a spectrometer (4). The spectrum is analysed by the spectrometer operating software, and given in intensity versus wavelength charts (I-W). The data were processed and presented in terms of the corresponding temperatures. 


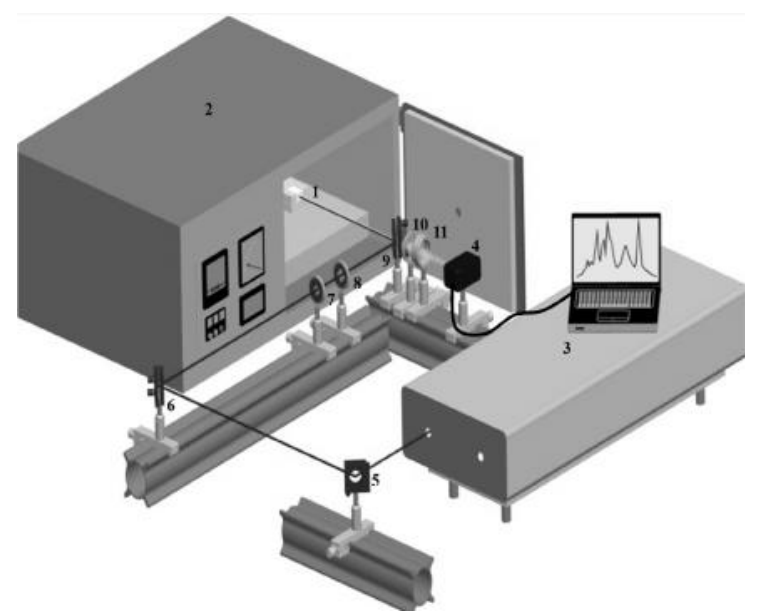

Fig. 1. A schematic of the experimental setup. 1: Phosphor sample. 2: Oven. 3: Pulsed Nd:YAG UV laser at 355nm. 4: Spectrometer. 5, 6 and 9: High reflective mirrors at $355 \mathrm{~nm}$. 7: Cylindrical lens for a focal length of $1000 \mathrm{~mm}$. 8: Cylindrical lens for a focal length of 750 $\mathrm{mm}$. 10: Focusing lens for a focal length of $100 \mathrm{~mm}$. 11: Two longpass edge filters at $355 \mathrm{~nm}$.

The phosphor was Dy:Er:YAG. The chemical composition was: $1.5 \%$ Dy and $0.5 \%$ Er. The selection principle for these ratios was relied on their optimal emissions after excitation. That is, the phosphorescence intensity increased by adding $0.5 \%$ of Er, whereas adding more than $1.5 \%$ of Dy did not enhance the signal intensity that much because of saturation effects and/or self quenching. The phosphor powder was prepared using a top-down approach; a phosphor crystal is transferred to a microstructured form $[47,48]$. The Dy:Er:YAG monocrystal is made by crystal growth in a melting chamber then mechanically pulverised in a jet mill to produce particles with diameters of about $3 \mu \mathrm{m}$. The particle size distribution was also controlled by a laser diffraction technique $[49,50]$.

The optical parts were mounted and attuned so as to provide a high optical efficiency as follows:

1. Three highly reflective mirrors at $355 \mathrm{~nm}(5),(6)$ and (9) were installed to transmit the laser beam to the sample in the oven.

2. Two cylindrical lenses (7) and (8) with a focal length of $1000 \mathrm{~mm}$ and $750 \mathrm{~mm}$, respectively were placed in the laser beam path between the mirrors (6) and (9) to obtain a sharp focusing of the laser beam.

3. A collecting lens (10) for a focal length of $100 \mathrm{~mm}$ was mounted behind the dichroic mirror (9) for higher transmissions of the phosphorescence spectra.

4. Two long-pass edge filters (11) at $355 \mathrm{~nm}$ were adjoined at the back of (10) to reduce the reflected light of $355 \mathrm{~nm}$. A second long-pass filter was added since one long-pass edge filter was insufficient for the reduction.

The challenges of low signal intensity at high temperatures were overcome by subtracting the strong blackbody radiation effect and background noise from the phosphorescence spectrum. It was accumulated by 5 averaged spectra each with an integration time of $300 \mathrm{~ms}$ to decrease the noise. These were achieved by using the spectrometer software [51].

It is vital to note that the particular approach followed for preparing the phosphor, accompanied by enhancing its chemical composition, plus using a spectrometer with an accuracy order of fractions of nanometres and the precise adjustments for the optical components, all together played the major role to meet the objectives of this study.

\section{Discussion of Results}

The LIP spectral distribution in terms of NDI-W and its intensity expressed in NI and IR are used for temperature calibrations at extreme conditions. The impact of applying a broad range of laser power levels on these calibrations was conducted as well. The results for NDI-W at LPL 2 for different temperatures are shown in Figs. 2-5. Outcomes on the behaviour of NI are expressed using six strategies at LPL 2 are also shown in Fig. 6. Also, results of the behaviour of IR calculated in three ways at LPL 2 are presented (see Fig. 7). The influence of LPL increase on the NDI-W, NI and IR are given in Figs. 8-11 as well. The $\mathrm{SD}_{\mathrm{p}}$ used to represent the temperature measurements precision is calculated as well for the aforesaid calibrations.

Figures 2-5 present the NDI-W phosphorescence behaviour at LPL 2 in the variety of $20-1800{ }^{\circ} \mathrm{C}$. The maximum intensity in the range $490-500 \mathrm{~nm}$ (hatched areas) is used for nondimensionalising the intensities in the temperature range of 20$1400{ }^{\circ} \mathrm{C}$. The maximum intensity at $390-400 \mathrm{~nm}$ and $382-387$ $\mathrm{nm}$ (hatched areas) was used for the range $1450-1750{ }^{\circ} \mathrm{C}$ and $1800^{\circ} \mathrm{C}$, respectively.

The behaviour of phosphorescence is given as follows: the intensities rise in the range $450-470 \mathrm{~nm}$ with temperatures increase in the range $20-1200{ }^{\circ} \mathrm{C}$ and drops in the domain 1250$1400{ }^{\circ} \mathrm{C}$ reaching their maximum values at the wavelengths of $455-458 \mathrm{~nm}$ as indicated by waved areas in Figs. 2-4.

Figure 5 shows spectra recorded in the range of 1450-1800 ${ }^{\circ} \mathrm{C}$. It is noticed that the performance of non-dimensionalised intensities does not have either a particular description in the range $370-380 \mathrm{~nm}$ or in $380-400 \mathrm{~nm}$. The recorded emissions were only in the range of $370-400 \mathrm{~nm}$ and there were not any phosphorescence signals detected in the range of $400-500 \mathrm{~nm}$. The spectra in this range are governed by the blackbody radiation effect, forming a curvature of polynomial with intensity values much higher than those for phosphorescence. This curvature is removed from the phosphorescence emissions using the software by storing the dark spectrum and the background first, then subtracting them from each spectrometer channel.

Despite the characterisation of recorded spectra in the range $370-400 \mathrm{~nm}$ (which are also resulting from laser-induced plasma emissions) is not clear, it is still valid for measuring temperatures in the range $1400-1800{ }^{\circ} \mathrm{C}$ (see Figs. 5-7).

Temperatures are measured in the NDI-W charts by using two principles as follows: a. Signals cross-checking, wherein a spectrum of phosphorescence from a combustion application is put into figures 2-5 and compared to the most fitting signal. b. The non-dimensionalised intensities in the range $455-458 \mathrm{~nm}$ for temperatures $20-1400{ }^{\circ} \mathrm{C}, 377-378 \mathrm{~nm}$ for $1450-1750{ }^{\circ} \mathrm{C}$ and $374-375 \mathrm{~nm}$ for $1800{ }^{\circ} \mathrm{C}$. Though the NDI-W charts clearly described the phosphorescence behaviour using the domain $455-458 \mathrm{~nm}$, but it neither did show the performance in terms of maximum intensities nor for a specified wavelength. These matters are quite important for temperature measurements in case of interference with combustion chemiluminescent radicals, called also the radical emissions of combustion, e.g., $\mathrm{CO}$ and $\mathrm{C}_{2}$. The former occurs at a wavelength of around 450 $\mathrm{nm}$ and the latter at about $440 \mathrm{~nm}$ and $470 \mathrm{~nm}[52,53]$. NI charts were formed to clarify these issues; an arbitrary value of 20,000 was used for normalisation.

The behaviour of NI at LPL 2 is described in six strategies: $\mathrm{I}_{\text {Max(Blue) }}, \mathrm{I}_{\text {Max(Red) }}, \mathrm{I}_{455.02 \mathrm{~nm}}, \mathrm{I}_{497 \mathrm{~nm}}, \mathrm{I}_{452.06 \mathrm{~nm}}$, and $\mathrm{I}_{496.5 \mathrm{~nm}}$. The first two strategies interpret that the peak/bright spectrum lines must be chosen in two areas for temperature estimations. These areas are called "blue" and "red" regions ranging from 450-460 
$\mathrm{nm}$ and $490-500 \mathrm{~nm}$, respectively. This rule is suitable for temperature measurements varying from $20-1400{ }^{\circ} \mathrm{C}$. Another criterion is taken for $1450-1750^{\circ} \mathrm{C}$ reads $370-380 \mathrm{~nm}$ and 390 $400 \mathrm{~nm}$ which must be applied for the blue and red areas, respectively. A new rule was made for $1800{ }^{\circ} \mathrm{C}$ whereas 370 $375 \mathrm{~nm}$ for the blue region and $382-387 \mathrm{~nm}$ for the red one.

It is vital to note that the first two strategies represent the signals performance of most sensitive phosphor spectral lines and cover a wide range of temperature variation $20-1800{ }^{\circ} \mathrm{C}$. On the contrary, the other four strategies are detecting the emissions of selected spectral lines specifically $455.02 \mathrm{~nm}, 497$ $\mathrm{nm}, 452.06 \mathrm{~nm}$ and $496.5 \mathrm{~nm}[3,45]$ regardless of the related intensities. The spectral lines carrying local changes at a certain point are characterised by high sensitivity in the $1^{\text {st }}$ and $2^{\text {nd }}$ strategies, tends to be sensitive in $455.02 \mathrm{~nm}$, sensitive in $497 \mathrm{~nm}$, insensitive in $452.06 \mathrm{~nm}$ (no clear peak) and sensitive in 496.5 $\mathrm{nm}$. Therefore, the higher susceptibilities, the better the responses of transmitting topical alterations, are resulting in temperatures with higher accuracies.

The effect of temperature rise on the normalised intensities for different wavelengths at LPL 2 from $20-1800{ }^{\circ} \mathrm{C}$ is presented in Fig. 6 . The normalised intensity $\mathrm{I}_{\mathrm{Max}(\mathrm{Blue})}$ rises with temperature ascending in the range of $20-900{ }^{\circ} \mathrm{C}$ and then decreases from $900-1800{ }^{\circ} \mathrm{C}$. The corresponding wavelengths were varying from $457.88-456.06 \mathrm{~nm}$ and $456.06-374.51 \mathrm{~nm}$, respectively. At $455.02 \mathrm{~nm}$ and $452.06 \mathrm{~nm}$ the intensity ascends up to $900{ }^{\circ} \mathrm{C}$ as the temperature increases and then decreases in the domain $900-1400{ }^{\circ} \mathrm{C}$. $\mathrm{I}_{\mathrm{Max}(\operatorname{Red})}, \mathrm{I}_{497 \mathrm{~nm}}$ and $\mathrm{I}_{496.5 \mathrm{~nm}}$ descend in the range $20-350{ }^{\circ} \mathrm{C}$. After $350{ }^{\circ} \mathrm{C}$, the intensities stay increasing reaching their maximum values at $900{ }^{\circ} \mathrm{C}$, then keep decreasing.

Temperatures are measured in NI charts by using the normalised intensities and the associated strategy. Although this way is more comprehensive than NDI-W, describing the performance of LIP in detailed view, but it has spectral lines of low slopes in a number of temperature ranges. Higher slopes can be attained using these ratios: $\mathrm{I}_{\operatorname{Max}(\text { Blue })} / \mathrm{I}_{\operatorname{Max}(\text { Red })}$, $\mathrm{I}_{455.02 \mathrm{~nm}} / \mathrm{I}_{497 \mathrm{~nm}}$ and $\mathrm{I}_{452.06 \mathrm{~nm}} / \mathrm{I}_{496.5 \mathrm{~nm}}$. They form what is called IR diagrams. The first ratio/way is adapted and the other two ways are quoted in the literature $[3,45]$. The influence of temperature rise on intensity ratios at LPL 2 is presented in Figure 7. It is seen that the intensity ratios produced from the second way (I455.02nm/I497nm) are always higher than those found in the first method ( $\left.\mathrm{I}_{\mathrm{Max}(\mathrm{Blue})} / \mathrm{I}_{\mathrm{Max}(\mathrm{Red})}\right)$. Also, these values differ slightly in the temperature range $20-1000{ }^{\circ} \mathrm{C}$ and significantly in the range of $1050-1400{ }^{\circ} \mathrm{C}$ than those in the first method. It was also observed that the intensity ratios in the $1^{\text {st }}$ and $2^{\text {nd }}$ ways are always higher than those in the third way. The maximum intensity ratios occurred at $1200{ }^{\circ} \mathrm{C}$ for the $1^{\text {st }}$ and the $2^{\text {nd }}$ ways, correspondingly and at $1400{ }^{\circ} \mathrm{C}$ for the $3^{\text {rd }}$ way $\left(\mathrm{I}_{452.06 \mathrm{~nm}} / \mathrm{I}_{496.5 \mathrm{~nm}}\right)$.

The behaviour of intensity ratio has the same description, either in the $1^{\text {st }}$ or $2^{\text {nd }}$ way, whereas it differs in the $3^{\text {rd }}$ one. It ascends with temperature from $20-1200{ }^{\circ} \mathrm{C}$ and then drops until $1800{ }^{\circ} \mathrm{C}$ and $1400{ }^{\circ} \mathrm{C}$ in the $1^{\text {st }}$ and $2^{\text {nd }}$ ways, respectively, while it remains rising from $20-1400{ }^{\circ} \mathrm{C}$ in the $3^{\text {rd }}$ way. An abrupt increment is found in the intensity ratios with temperatures rising in the range $100-400{ }^{\circ} \mathrm{C}$ in means 1 and 2 , more than in 3. A sharper increase was also seen in the intensity ratios in all methods with temperatures varying from $400-1000{ }^{\circ} \mathrm{C}$, greater than that found in $100-400{ }^{\circ} \mathrm{C}$. That is, the slope in the former ranges is greater in methods 1 and 2 than 3 , results in the higher slopes, the better the accuracy. Also, the slope in method 2 remains almost constant with temperature ascending in the range $1000-1150{ }^{\circ} \mathrm{C}$. After that, the slope has very small values in the range $1150-1250{ }^{\circ} \mathrm{C}$ whereas a sharp decrease is found in the range $1250-1400{ }^{\circ} \mathrm{C}$.
It is vital to note that the accuracies in terms of slopes are unrelated to those as mentioned before in terms of susceptibilities.

Concerning the $1^{\text {st }}$ way, as with 2 , the accuracies are highest in the variety of $100-1000{ }^{\circ} \mathrm{C}$ reaching slightly lower values than those for the $2^{\text {nd }}$ method. The slope also has high values in the range of $1350-1600^{\circ} \mathrm{C}$ and very low values in the variety of $1000-1350{ }^{\circ} \mathrm{C}$ and $1600-1800{ }^{\circ} \mathrm{C}$.

The accuracy in method 3 has high values in the range 400$1300{ }^{\circ} \mathrm{C}$, lower in $100-400{ }^{\circ} \mathrm{C}$ and lowest at $1300-1400{ }^{\circ} \mathrm{C}$. As a consequence, method 3 can be applied for temperature measurements from $20-1400{ }^{\circ} \mathrm{C}$, whereas method 1 and 2 provide higher accuracies in terms of slopes up to $1050{ }^{\circ} \mathrm{C}$ and $1150^{\circ} \mathrm{C}$, respectively. Also, a previous knowledge of operating temperatures is required if method 1 and 2 are used for measuring temperatures greater than $750{ }^{\circ} \mathrm{C}$ and $1050{ }^{\circ} \mathrm{C}$, respectively.

Temperatures are measured in IR calibration curves using the ratio and the corresponding way.

It was also revealed that the NDI-W calibration curves at different laser power levels do not offset one another as seen in Fig. 8. This means that for a certain temperature, the intensity is almost identical irrespective of the laser power level applied. On the contrary, a significant offset is found for NI calibration curves either in the blue or red areas under the same conditions (see Figs. 9-10). This confirms a monotone increase of phosphorescence intensity with increasing the laser power without saturation effects. The IR calibration curves at different laser power levels were identical with no offset (see Fig. 11).

The temperature measurements were repeated five times wherein the precision in terms of the SDp was around $\pm 1.35 \%$ for NDI-W, $\pm 1.41 \%$ for NI, $\pm 0.73 \%$ for the adapted IR method (1), $\pm 1.15 \%$ and $\pm 0.50 \%$ for the other two IR methods.

The accuracy of furnace temperature was tested using a thermocouple device, which has a maximum operating temperature of $1370{ }^{\circ} \mathrm{C}$. The furnace temperature was taken as a true value, as it provides reproducible digital readings with an accuracy of $\pm 2{ }^{\circ} \mathrm{C}$. It was found that for oven operating temperatures, such as $20{ }^{\circ} \mathrm{C}$ and $1350{ }^{\circ} \mathrm{C}$, the thermocouple equivalent temperatures were $22^{\circ} \mathrm{C}$ and $1368{ }^{\circ} \mathrm{C}$, respectively. The mean absolute percentage error (MAPE) is, therefore, $10 \%$ in the former case and $1 \%$ in the latter. That is, the higher the temperature, the better the accuracy. The MAPE is given as follows: $\left|\mathrm{T}_{\text {Oven }}-\mathrm{T}_{\text {Themocouple }}\right| / \mathrm{T}_{\text {Oven }}$.

The ambient conditions were taken to verify the conditions applied; they might have a slight impact on the results presented. The ambient pressure was around 0.988 bar during the entire experiments, while the ambient temperatures varied from $18.7-21^{\circ} \mathrm{C}$ reaching a minimum of $17.9^{\circ} \mathrm{C}$. That is, the ambient temperature changed in a quite small range compared with the wide variation of $20-1800{ }^{\circ} \mathrm{C}$. That is why the oven is always providing temperatures within $\pm 2{ }^{\circ} \mathrm{C}$.

The heating time of the phosphor sample was also measured. The heating time sharply ascends as the oven temperature increases within the range $20-200{ }^{\circ} \mathrm{C}$, reaching maximum of around $6 \mathrm{~min}$ at $250{ }^{\circ} \mathrm{C}$. Conversely, as the furnace temperature increases in the range of $250-400{ }^{\circ} \mathrm{C}$, the heating time steeply decreases followed by a slight drop as the oven temperature rises reaching minimum of $4 \mathrm{~min}$ at $1800{ }^{\circ} \mathrm{C}$.

The results of this research clearly confirmed that temperature measurements using NID-W, NI and IR are attainable at extremely adverse conditions provided proper selections of the signal wavelength and temperature range. The laser power variations did neither affect the nondimensionalised intensity nor the intensity ratio used for temperature calibrations. 


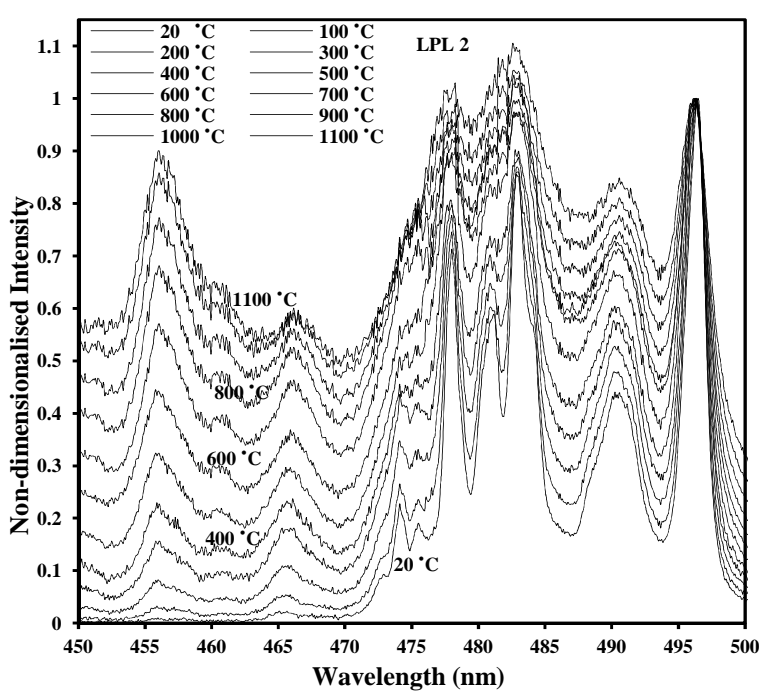

Fig. 2. Variation of non-dimensionalised intensity for different wavelengths at laser power level 2 and twelve temperature values (20 ${ }^{\circ} \mathrm{C}$ and $100-1100{ }^{\circ} \mathrm{C}$ in increments of 100 degrees Celsius).

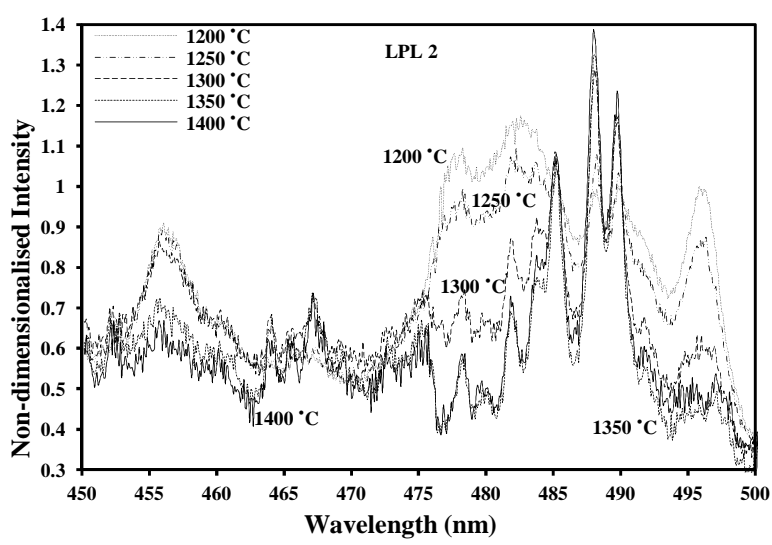

Fig. 4. Variation of non-dimensionalised intensity for different wavelengths at laser power level 2 and five temperature values (1200$1400{ }^{\circ} \mathrm{C}$ in increments of 50 degrees Celsius).

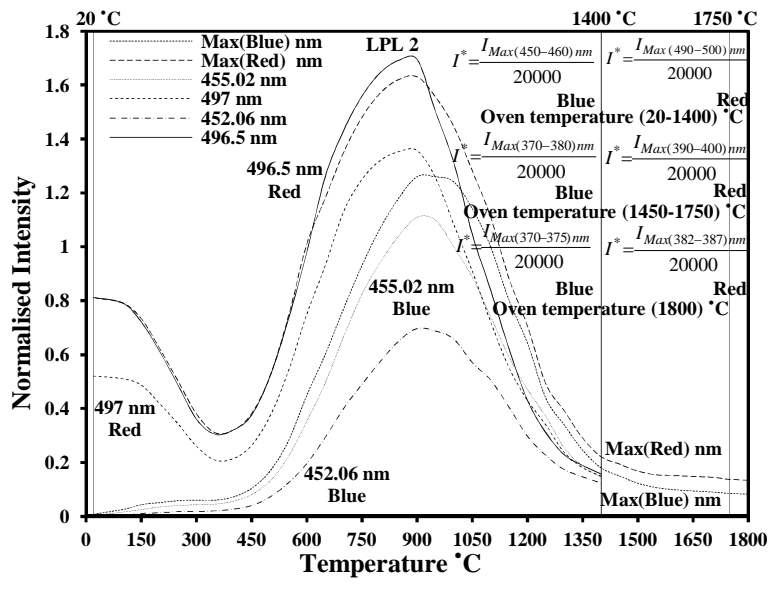

Fig. 6. Variation of normalised intensity for different temperatures at laser power level 2 in terms of normalised maximum intensity and normalised intensity for given wavelengths in the blue and red areas.

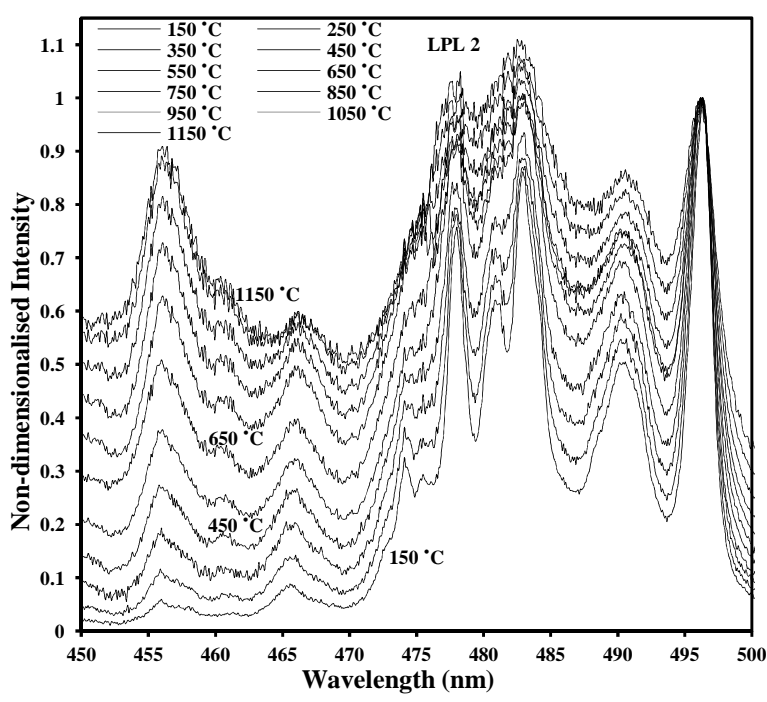

Fig. 3. Variation of non-dimensionalised intensity for different wavelengths at laser power level 2 and eleven temperature values (150$1150{ }^{\circ} \mathrm{C}$ in increments of 100 degrees Celsius).

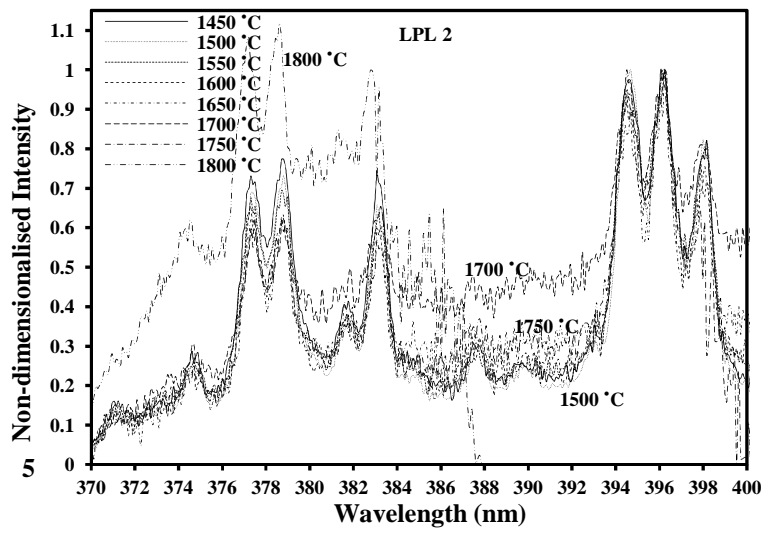

Fig. 5. Variation of non-dimensionalised intensity for different wavelengths at laser power level 2 and eight temperature values (1450$1800{ }^{\circ} \mathrm{C}$ in increments of 50 degrees Celsius).

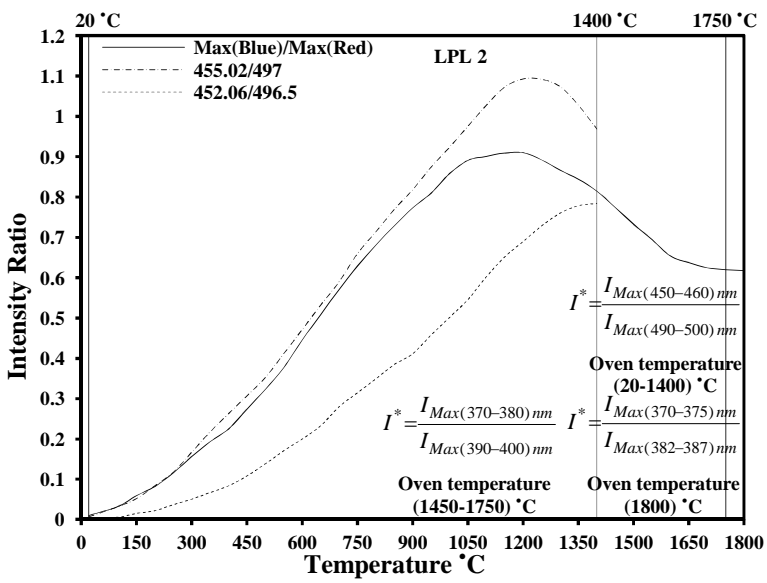

Fig. 7. Variation of intensity ratio for different temperatures estimated in three ways at laser power level 2. 


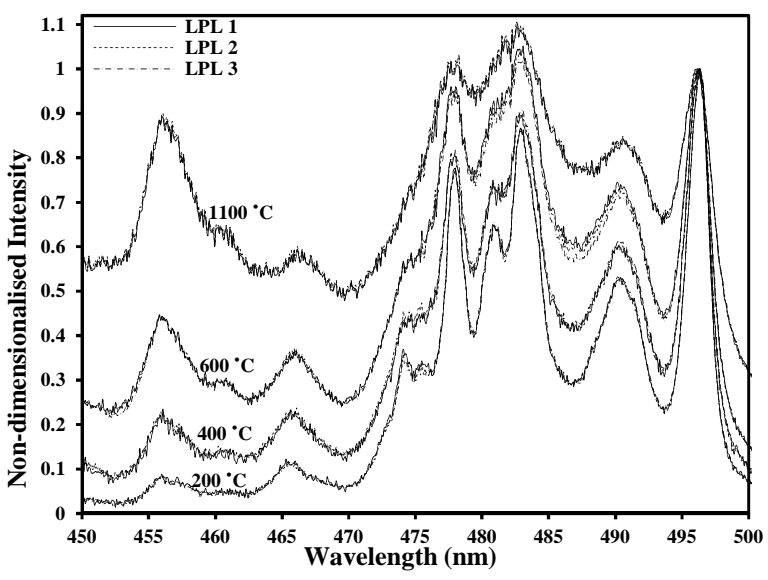

Fig. 8. Influence of laser power level increase on non-dimensionalised intensity for different wavelengths and for four temperature values 200 ${ }^{\circ} \mathrm{C}, 400{ }^{\circ} \mathrm{C}, 600{ }^{\circ} \mathrm{C}$ and $1100{ }^{\circ} \mathrm{C}$.

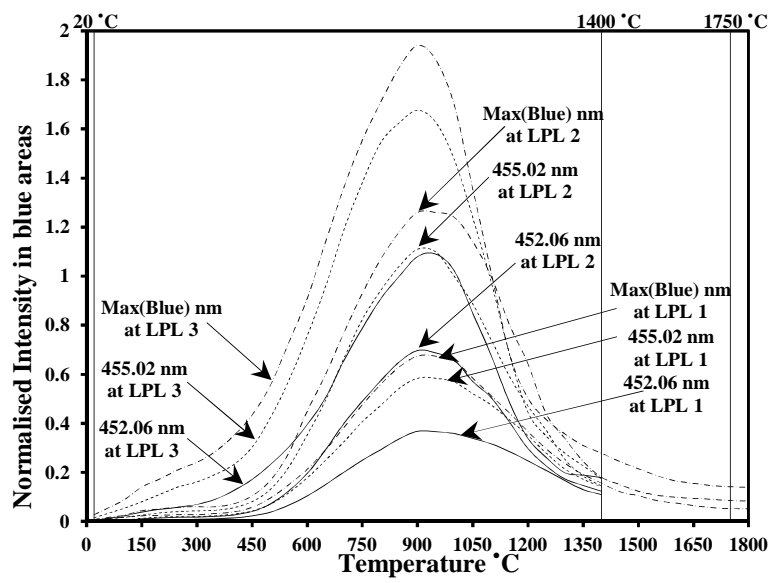

Fig. 9. Influence of laser power level increase on normalised maximum intensity and normalised intensity in the blue areas for given wavelengths and for different temperatures.

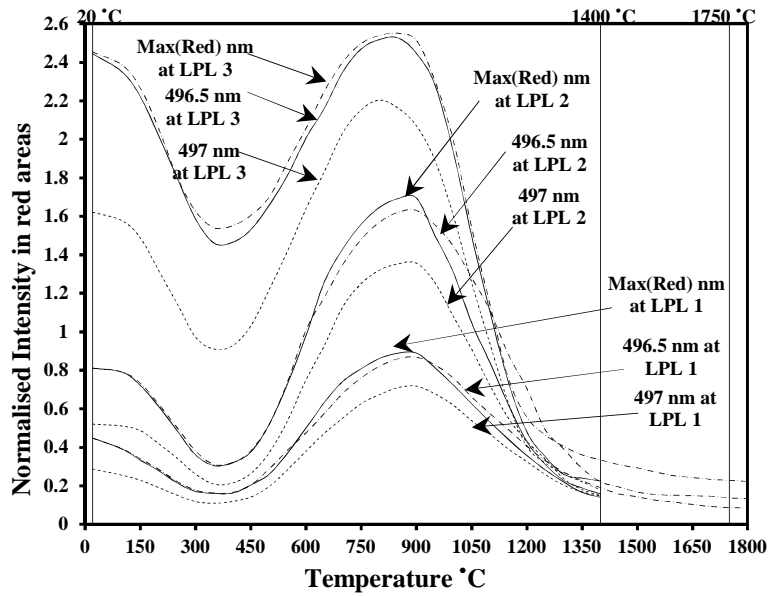

Fig. 10. Influence of laser power level increase on normalised maximum intensity and normalised intensity in the red areas for given wavelengths and for different temperatures.

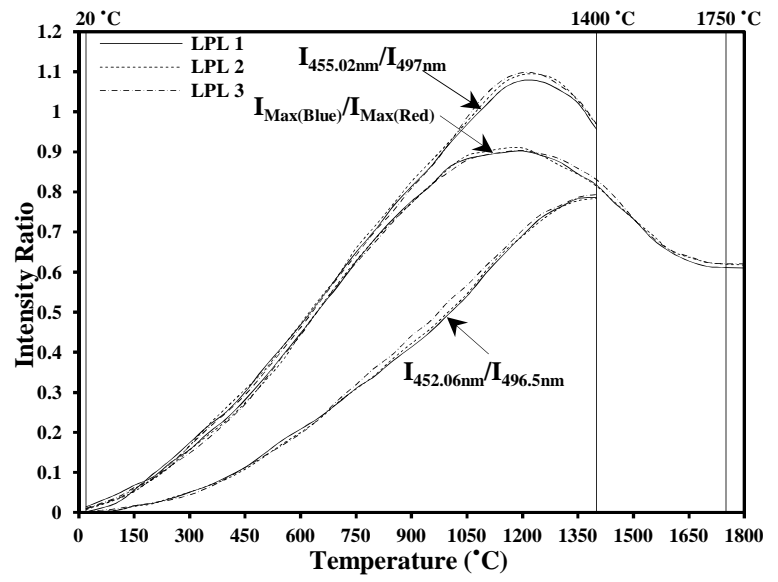

Fig. 11. Influence of laser power level increase on intensity ratio calculated in three ways for different temperatures.

\section{Summary, Conclusions and Recommendations}

A LIP technique for temperature measurements varying from 20-1800 ${ }^{\circ} \mathrm{C}$ was adjusted to develop a measurement method with higher precisions and accuracies than for other non-intrusive means. The Phosphor chemical composition was: $1.5 \%$ Dy and $0.5 \%$ Er double-doped:YAG. The emission distribution of phosphorescence expressed in NDI-W and its intensity in terms of NI and IR were used for temperature assessments. An adapted IR way was employed for temperature calculations and other two IRs were also used for validation. The precision was represented in terms of the $\mathrm{SD}_{\mathrm{p}}$, the accuracy of oven temperature was tested using a thermocouple and made in the MAPE, the ambient conditions and the heating time of the phosphor specimen were investigated. The survivability and consistency of using white phosphor at hostile conditions werealso confirmed.

Based on the results of this investigation, the following conclusions may be stated:

- Temperature measurements are obtainable at excessively hostile conditions, presenting proper selections of the signal wavelength and temperature range.

- The way of preparation followed for white phosphor powder together with chemical composition improved were the essential reasons for attaining appropriate signals.

- The precise modifications for the optical parts besides using a spectrometer with an accuracy order of fractions of nanometres, effectively supported along with the point above to meet the objectives of this study.

- The phosphorescence in the NDI-W charts increases in the range $450-470 \mathrm{~nm}$ with temperatures varying from $20-1200{ }^{\circ} \mathrm{C}$ and drops in $1250-1400^{\circ} \mathrm{C}$ reaching at $455-458 \mathrm{~nm}$ their maximum values.

- The blackbody radiation effect poses an enormous obstacle to proper phosphoresce emissions at extremely high temperatures particularly in the range of $1450-1800^{\circ} \mathrm{C}$.

- The first and the second strategies had the lead to include a broader temperature range of $1400-1800^{\circ} \mathrm{C}$ whereas the others do not. 
- $\quad$ The normalised intensity in the 6 strategies reached its maximum value at $900{ }^{\circ} \mathrm{C}$.

- $\quad$ The spectral lines possess high sensitivity, i.e., clear peaks, the better the response of conveying local changes, the higher the temperature accuracies.

- The wavelengths used for temperature calibrations must be carefully selected to avoid interferences with chemiluminescent radicals found in combustion applications.

- The first two strategies $\mathrm{I}_{\mathrm{Max}(\text { Blue) }}$ and $\mathrm{I}_{\mathrm{Max}(\operatorname{Red})}$ attributed to their high sensitivities have the highest temperature accuracies.

- The intensity ratio in the $1^{\text {st }}$ method had an advantage of involving a temperature range of $20-1800{ }^{\circ} \mathrm{C}$ while the other two do not.

- The maximum intensity ratio in the first two methods arose at $1200{ }^{\circ} \mathrm{C}$ and it differs in the third one to occur at $1400{ }^{\circ} \mathrm{C}$.

- The effect of laser radiation on particles heating is negligible.

- The NDI-W curves at different laser power levels do not offset one another, while a big offset is found for NI curves.

- $\quad$ The intensity ratios in IR charts were almost identical in each way without offset irrespective to the laser power level used.

- $\quad$ The $\mathrm{SD}_{\mathrm{p}}$ was around $\pm 1.35 \%$ for NDI-W, $\pm 1.41 \%$ for NI, $\pm 0.73 \%$ for the adapted IR method, $\pm 1.15 \%$ and $\pm 0.50 \%$ for the other two methods.

- The MAPE of the thermocouple varied from the lowest to the highest temperature $\left(20-1350{ }^{\circ} \mathrm{C}\right)$ to be $10-1 \%$, that is, the higher the temperature, the better the accuracy.

Building on this research, we highly recommend the following ideas for future work:

1. Optimising chemical composition of other phosphors, may enhance the LIP signals.

2. The same measurements may be conducted for a mixture of Dy:Er:YAG and an adhesive agent with different concentrations applied either to impermeable or porous surfaces, e.g., in PMBs [12] as a coating layer.

3. Advanced phosphor coating techniques are appropriate for points 1 and 2 .

4. The same measurements could be conducted for different adhesive agents.

5. Other stimulation wavelengths may also be tested in the same way described in the previous points.

\section{Acknowledgements}

The author gratefully acknowledges financial support from the German Academic Exchange Service (DAAD) and the German Research Foundation (DFG) which also funds the Erlangen Graduate School in Advanced Optical Technologies (SAOT) in the framework of the German Excellence Initiative. The author is also grateful to the Applied Science Private University, Amman, Jordan for the financial support granted to this research project (Grant No. DRGS-2014-2015-206). Thanks also go to Dipl.-Ing. Marius Wesmas-Murgu for his technical support and PD Dr. Miroslaw Batentschuk (Institute of Materials for Electronics and Energy technology, University of Erlangen) for the phosphor powder preparation.

\section{References}

[1] Jordan, J. and Rothamer, D. Thermographic phosphor based planar thermometry using the trivalent Praseodymium ion $(\mathrm{Pr} 3+)$ doped into a yttrium aluminum garnet (YAG) crystal. (Spring Technical Meeting of the Central States Section of the Combustion Institute, University of Dayton and the Air Force Research Laboratory, Dayton, Ohio, USA, April 22-24, 2012) pp. 1-11. 2012.

[2] Lindén, J., Takada, N., Johansson, B., Richter, M., and Aldén, M., Investigation of potential laserinduced heating effects when using thermographic phosphors for gas-phase thermometry. Applied Physics B: Lasers and Optics, 2009. 96(02): p. 237240.

[3] Yu, M., Särner, G., Luijten, C., Richter, M., Aldén, M., Baert, R., and de Goey, L., Survivability of thermographic phosphors (YAG:Dy) in a combustion environment. Measurement Science and Technology, 2010. 21(03): p. 1-4.

[4] Omrane, A., Särner, G., and Aldén, M., 2Dtemperature imaging of single droplets and sprays using thermographic phosphors. Applied Physics B: Lasers and Optics, 2004. 79(04): p. 431-434.

[5] Hasegawa, R., Sakata, I., Yanagihara, H., Johansson, B., Omrane, A., and Aldén, M., Two-dimensional gas-phase temperature measurements using phosphor thermometry. Applied Physics B: Laser and Optics, 2007. 88(02): p. 291-296.

[6] Aldén, M., Omrane, A., Richter, M., and Särner, G., Thermographic phosphors for thermometry: A survey of combustion applications. Progress in Energy and Combustion Science, 2011. 37(04): p. 422-461.

[7] Buck, G., Quantitative surface temperature measurement using two-color thermographic phosphors and video equipment. Appl. No. 205,900 (United States patent, represented by the administrator of the national aeronautics and space administration, Washington, DC, USA) pp. 1-3. Patent No. 4,885,633. 1989.

[8] Särner, G., Richter, M., and Aldén, M., Investigations of blue emitting phosphors for thermometry. Measurement Science and Technology, 2008. 19(12): p. 1-10.

[9] Feist, J., Heyes, A., and Seefelt, S., Thermographic phosphor thermometry for film cooling studies in gas turbine combustors. The Proceedings of the Institution of Mechanical Engineers: Part A, Journal of Power and Energy, 2003. 217(02): p. 193-200.

[10] Feist, J. and Heyes, A. Measurement of wall temperatures in gas turbine combustors using thermographic phosphors. (The 15th International Symposium on Air Breathing Engines, Bangalore, India, September, 3-7 2001) pp. 1-13. . 2001.

[11] Allison, S. and Gillies, G., Remote thermometry with thermographic phosphors: Instrumentation and applications. Review of Scientific Instruments, 1997. 68(07): p. 2615-2650. 
[12] Jaber, A., Zigan, L., Sakhrieh, A., and Leipertz, A. Surface temperature distribution remote phosphor thermometry of a porous media burner using laserinduce phosphorescence intensity measurements. (The 34th international symposium on combustion, Warsaw University of Technology, Warsaw, Poland, July 29, -August 03, 2012). 2012.

[13] Jaber, A., Zigan, L., Sakhrieh, A., and Leipertz, A. Laser-induced phosphorescence in combustion diagnostics: calibration at extremely high temperatures. (The 11th international conference on combustion and energy utilization (ICCEU), Hotel Dona Ines, Coimbra, Portugal, 09-13 May 2012) pp. 1-9. 2012.

[14] Bosze, E., Hirata, G., and McKittrick, J., An analysis of Y2O3 Eu3+ thin films for thermographic phosphor applications. Journal of luminescence, Elsevier Science Publishers, 2011. 131(01): p. 41-48.

[15] Hansel, R., Phosphor thermometry using rare-earth doped materials. PhD thesis. 2010, Vanderbilt University: Nashville, Tennessee, USA.

[16] Omrane, A., Ossler, F., Aldén, M., Svenson, J., and Pettersson, J.B.C., Surface temperature of decomposing construction materials studied by laserinduced phosphorescence. Fire and Materials, 2005. 29(01): p. 39-51.

[17] Rabhiou, A., Kempf, A., and Heyes, A. Examination of Eu-doped thermographic phosphors for surface temperature measurements. (The 4th European Combustion Meeting, Vienna University of Technology, Vienna, Austria, April 14-17, 2009) pp. 1-6. 2009.

[18] Goss, L., Smith, A., and Post, M., Surface thermometry by laser-induced fluorescence. Review of scientific instruments, the American institute of physics, 1989. 60(12): p. 3702-3706.

[19] Bruebach, J., Patt, A., and Dreizler, A., Spray thermometry using thermographic phosphors. Applied Physics B: Laser and Optics, Physics and Astronomy, 2006. 83(04): p. 499-502.

[20] Khalid, A.H. and Kontis, K., Progress towards absolute intensity measurements of emissions from high temperature thermographic phosphors. Journal of Luminescence, 2011. 131(07): p. 1312-1321.

[21] Alaruri, S., Brewington, A., Thomas, M., and Miller, J., High-temperature remote thermometry using laser-induced fluorescence decay lifetime measurements of Y2O3:Eu and YAG:Tb thermographic phosphors. IEEE Transactions on Instrumentation and Measurement, 1993. 42(03): p. 735-739.

[22] Khalid, A. and Kontis, K., 2D surface thermal imaging using rise-time analysis from laser-induced luminescence phosphor thermometry. Measurement Science and Technology, 2009. 20(02): p. 1-9.

[23] Atakan, B., Eckert, C., and Pflitsch, C., Light emitting diode excitation of $\mathrm{Cr} 3+\mathrm{Al} 2 \mathrm{O} 3$ as thermographic phosphor: experiments and measurement strategy. Measurement Science and Technology, 2009. 20(07): p. 1-9.
[24] Pflitsch, C., Siddiqui, R., and Atakan, B., Phosphorescence properties of sol-gel derived ruby measured as functions of temperature and Cr3+ content. Applied Physics A: Materials Science \& Processing, Physics and Astronomy, 2008. 90(03): p. 527-532.

[25] Noel, B.W., Borella, H.M., Lewis, W., Turley, W.D., Beshears, D.L., Capps, G.J., Cates, M.R., Muhs, J.D., and Tobin, K.W., Evaluating thermographic phosphors in an operating turbine engine. 1989. Medium: ED; Size: Pages: (13 p).

[26] Allison, S., Beshears, D., Bencic, T., Hollerman, W., and Boudreaux, P. Development of temperaturesensitive paints for high temperature aeropropulsion applications. (The 37th AIAA/ASME/SAE/ASEE Joint Propulsion Conference and Exhibit, Salt Lake City, Utah, USA, July 8-11, 2001) pp. 1-8. 2001.

[27] Allison, S., Cates, M., Noel, B., and Gillies, G., Monitoring permanent-magnet motor heating with phosphor thermometry. Transactions on Instrumentation and Measurement, IEEE, 1988. 37(04): p. 637-641.

[28] Tobin, K., Allison, S., Cates, M., Capps, G., Beshears, D., Cyr, M., and Noel, B., Hightemperature phosphor thermometry of rotating turbine blades. Instrumentation and Photography: AIAA Journal, 1988. 28(08): p. 1485-1490.

[29] Feist, J., Heyes, A., and Seefeldt, S., Oxygen quenching of phosphorescence from thermographic phosphors. Measurement Science and Technology, 2003. 14(05): p. N17-N20.

[30] Heyes, A., On the design of phosphors for hightemperature thermometry. Journal of Luminescence, 2009. 129(12): p. 1-6.

[31] Feist, J., Heyes, A., and Seefeldt, S. Thermographic phosphors for gas turbines: Instrumentation development and measurement uncertainties. (The 11th International symposium on application of laser techniques to fluid mechanics, The Calouste Gulbenkian Foundation, Lisbon, Portugal, July 8-11, 2002) pp. 1-12. 2002.

[32] Bruebach, J., Dreizler, A., and Janicka, J., Gas compositional and pressure effects on thermographic phosphor thermometry. Measurement Science and Technology, 2007. 18(03): p. 764-770.

[33] Husberg, T., Girja, S., Denbratt, I., Omrane, A., Aldén, M., and Engström, J., Piston temperature measurements by use of thermographic phosphors and thermocouples in a heavy-duty diesel engine run under partly premixed conditions. SAE Technical Paper, 2005, No. 2005-01-1646.

[34] Bruebach, J., Zetterberg, J., Omrane, A., Li, Z., Aldén, M., and Dreizler, A., Determination of surface normal temperature gradients using thermographic phosphors and filtered Rayleigh scattering. Applied Physics B: Lasers and Optics, 2006. 84(03): p. 537-541.

[35] Omrane, A., Göransson, U., Ossler, F., Holmstedt, G., and Aldén, M. Surface temperature measurement of flame spread using thermographic phosphors. 
(The 7th International Association for Fire Safety Science (IAFSS) Symposium on Fire Safety Science, Evans D. D., Massachusetts, Boston, USA, June 1621, 2002) pp. 141-152. 2002.

[36] Allison, S., Beshears, D., Gadfort, T., Bencic, T., Eldridge, J., Hollerman, W., and Boudreaux, P. High temperature surface measurements using lifetime imaging of thermographic phosphors: bonding tests. (The 19th International Congress on ICIASF 2001: Instrumentation in Aerospace Simulation Facilities, Cleveland, Ohio, USA, August 27-30, 2001) pp. 171176. 2001.

[37] Hoelen, C., Borel, H., de Graaf, J., Keuper, M., Lankhorst, M., Mutter, C., Waumans, L., and Wegh, R. Remote phosphor LED modules for general illumination-towards $200 \mathrm{~lm} / W$ general lighting LED light sources. Vol. 7058, No. 70580M (Proceedings of SPIE, the 8th International Conference on Solid State Lighting, San Diego, California, USA, 11-13 August 2008) pp. 1-10. 2008.

[38] Yun-Chen, W., Teng-Ming, C., Chuang-Hung, C., and Chi-Neng, M., Luminescence and spectroscopic properties of yellow-emitting carbonitride phosphors and their application in white LEDs Journal of the Electrochemical Society, the Electrochemical Society, 2010. 157(10): p. J342-J346.

[39] Shikao, S. and Jiye, W., Combustion synthesis of Eu3+ activated Y3 Al5 O12 phosphor nanoparticles. Journal of Alloys and Compounds, Elsevier Science Publishers, 2001. 327(1, 2): p. 82-86.

[40] Laufer, G., Rotchford, N., and Krauss, R., Temperature field visualization in conducting solids using thermographic phosphors. American Journal of Physics: Physics education, 1997. 65(05): p. 447449.

[41] Bizzak, D. and Chyu, M., Rare-earth phosphor laserinduced fluorescence thermal imaging system. Review of Scientific Instruments, 1994. 65(01): p. 102-107.

[42] Chyu, M. and Bizzak, D., Surface temperature measurement using a laser-induced fluorescence thermal imaging system. Journal of Heat Transfer, 1994. 116(01): p. 263-266.

[43] Marino, R., Westring, B., Laufer, G., Krauss, R., and Whitehurst, R., Digital strain and temperature imaging technique. AIAA Journal, 1999. 37(09): p. 1097-1101.
[44] Särner, G., Laser-induced emission techniques for concentration and temperature probing in combustion. PhD Thesis. 2008, Lund University: Lund, Sweden.

[45] Nakayama, T. and Hamanoue, K., Reply to a comment on the dual phosphorescence of benzophenone in a water containing solvent at $77 \mathrm{~K}$. Chemical Physics Letters, 1991. 184(5, 6): p. 599601.

[46] Nabertherm GmbH, Nabertherm-Oefen: Supertherm HT 04/17, Operation Manual, (Bahnhofstrasse 20, D-2804 Lilienthal, Bremen Germany). C6.1/10.89. 1991.

[47] Weissgärber, T., Trends in nano powder production and applications. (The International Powder Metallurgy Directory IPMD, Inovar Communications Ltd, Shrewsbury, UK), 14th ed. 2010-2011. p. 1-7.

[48] Mansoori, G., Advances in Atomic and Molecular Nanotechnology. Tech Monitor. 2002. p. 53-59.

[49] Etzler, F. and Deanne, R., Particle size analysis: a comparison of various methods II. WILEY-VCH Verlagsgesellschaft, 1997. 14(6): p. 278-282.

[50] Tinke, A., Carnicer, A., Govoreanu, R., Scheltjens, G., Lauwerysen, L., Mertens, N., Vanhoutte, K., and Brewster, M., Particle shape and orientation in laser diffraction and static image analysis size distribution analysis of micrometer sized rectangular particles. Powder Technology, Elsevier Science Publishers, 2008. 186(2): p. 154-167.

[51] Ocean Optics Inc., SpectraSuite: Spectrometer Operating Software, Installation and Operation Manual, Preliminary Draft 8/24/2006.(Douglas Avenue 830, Dunedin, Florida, 34698 USA). 2006.

[52] Obertacke, R., Ein emissionstomographisches Sensorsystem für die Bestimmung zweidimensionaler Temperatur- und Radikalenfelder in Feuerungen. PhD Thesis. 1995, Friedrich-Alexander-Universitaet Erlangen-Nuernberg: Erlangen, Germany. Berichte zur Energie- und Verfahrenstechnik (BEV), ESYTEC, Erlangen, Germany. Schriftenreihe Heft 95.1. 3-9803413-4-8.

[53] Leipertz, A., Obertacke, R., and Wintrich, F., Industrial combustion control using UV emission tomography. Proceedings of the Combustion Institute, 1996. 26(02): p. 2869-2875. 